REVISTA ANDALUZA DE ANTROPOLOGÍA.

NÚMERO 5: APORTACIONES Y POTENCIALIDADES DE LA ANTROPOLOGÍA DE LA SALUD.

SEPTIEMBRE DE 2013

ISSN 2174-6796

[pp. 193-201]

http://dx.doi.org/10.12795/RAA.2013.i05.12

\title{
AAVV (2013). Repensando África. Perspectivas desde un enfoque multidisciplinar. Sevilla: Fundación Habitáfrica, 364 pp.
}

\author{
Ester Massó Guijarro \\ Universidad de Granada
}

\section{OBERTURA: ÁFRICA, AFRICANISMO, ESTUDIOS AFRICANOS... UNA REVISITA EPISTEMOLÓGICA Y UN LIBRO OPORTUNO}

En el último gran congreso de estudios africanos a nivel europeo ${ }^{1}$, recientemente celebrado en Lisboa, uno de los bajos continuos en las discusiones y mesas redondas era una revisión importante de las gramáticas mismas que usamos para hablar, pensar y estudiar sobre África -seamos o no africanos-, así como del carácter esencial de los denominados estudios africanos. La inquietud por la nomenclatura, la epistemología a la base de la misma y cómo nos definimos en tanto que estudiosas parece haber devenido uno de los puntos centrales de los estudios africanos contemporáneos, históricamente inter y multidisciplinarios, con singularidades no asimilables a otras áreas regionales o estudios de área; con sus particulares costumbres, celos, folclore incluso.

¿A qué nos referimos con "estudios africanos"? El uso adjetival de "africanos" sugeriría, en realidad, que hablamos de estudios realizados por personas africanas, pero no es así como lo entendemos (no siempre al menos) entre las bambalinas o sobre los santuarios

1. V European Conference on African Studies: "African dynamics in a multipolar world", 27-29 junio 2013, Lisboa (Portugal). 
disciplinarios, como bien ejemplifica la misma denominación de sus "romerías rituales", a saber, los mismos congresos de estudios africanos.

¿Cómo definimos África misma? ¿A qué obedece, u obedeció en sus inicios, la cada vez menos cómoda frontera ficticia entre África del norte y África subsahariana? El Sáhara nunca fue una barrera sino una vía porosa de intercambio, como cualquier otra frontera, orográfica, humana o en su conjugación geoestratégica. ¿Es África solo un lugar metafórico -en su intensa variabilidad y su amplitud kilométrica- sobre el que hablar, de modo unidireccional, o apuntamos cada vez más a un reconocimiento académico de África como lugar(es) autónomo(s) de producción de conocimiento, de agencia interdependiente frente al gran norte hegemónico?

El reciente libro que ahora reseñamos, necesariamente plural y policéntrico en sí mismo, viene a constituir, con gran oportunidad, un reflejo rico de este debate intrínseco al área y de actualidad insobornable; un debate tanto de nomenclatura, y la epistemología generalizada que subyace a su base, cuanto sobre la agencia y la política de los mismos estudios: ¿quiénes los hacen? ¿Cómo nombran a sus objetos-sujetos de estudio? ¿Qué debemos esperar y promover de los estudios africanos, de la cooperación académica y humana en general? ¿Qué podemos aprender, genuina, sinceramente, de África, más allá de retóricas fáciles y palabras gastadas?

$\mathrm{Y}$, ¿qué se está cociendo sobre tales cuestiones en los centros académicos españoles, andaluces para mayor concreción?

\section{PRESENTACIÓN GLOBAL Y HOLISMO DE LA OBRA}

"Para demostración de que es posible, y es necesario, aproximar todas las cosas para entender cada una" (Saramago, 2003: 467).

Reclamar África, las Áfricas en plural, de otra manera, no la África acuciante, necesitada, beneficiaria, sino la África en primera persona, con autonomía y dignidad intransferibles, ya es proverbial para los estudios africanos dentro y fuera de España. Así, ¿por qué sigue siendo necesario incidir en ello? Infelizmente, porque no es aún de conocimiento generalizado, más allá de los foros especializados, que África constituya mucho más que conflicto, violencia, tribalismo ancestral y primitivismo hambriento. Este libro viene virtualmente a cubrir una parte al menos de este importante y transversal hueco, bien notorio incluso en las aulas de las universidades. Los términos visibilización, significación, vindicación de epistemologías silenciadas, descolonización... dignidad, constituyen palabras clave de esta publicación.

El presente libro trasciende a la mera consistencia de un libro. Constituye el epítome escrito, por así decir, de un proyecto más amplio con el ambicioso objetivo de repensar 
África; revisitarla, reconsiderarla. La obra aquí reseñada constituye la plasmación final de una tarea colectiva de inquietudes diversas. Es la crónica escrita a muchas manos de las jornadas celebradas entre Sevilla y Granada durante marzo de 2012, y en cooperación de las universidades de dichas ciudades, asociaciones ciudadanas diversas y, especialmente, la Fundación Habitáfrica.

Dichas jornadas fueron parte del proyecto "Descubre África”, financiado por la Agencia Andaluza y Española de Cooperación Internacional al Desarrollo y promovido con el objetivo de enfatizar la presencia de África en las universidades andaluzas. Para su consecución se aunaron grupos de trabajo compuestos por profesorado y alumnado, organismos universitarios, ONGs y colectivos africanos. La web www.repensandoafrical. habitafrica.org, en el seno del proyecto, tuvo como fin la visibilización de dicho intercambio experiencial entre universidades españolas y africanas y sus diversas iniciativas al respecto.

En la presente obra se recogen algunas de las intervenciones y recapitulaciones de aquellos días de jornada. Veamos su esquema general. Se subdivide el libro en una introducción y unas conclusiones recapituladoras, entre las que discurren seis capítulos temáticos de desigual composición y extensión. Los grandes temas de cada capítulo, necesariamente vinculados pero, también, precisamente desagregados para su mejor abordaje, son los siguientes (siempre expresados en un muy significativo plural): géneros -cap. 1-, economías -cap. 2-, migraciones -cap. 3-, recursos naturales -cap. 4-, cooperación universidad-África-cap. 5-, y movimientos sociales -cap. 6-.

Este tratamiento desagregado delascuestioneses, como digo, necesario para poder analizar cada una con el tiempo y la atención justos; sin embargo, no se comprendería ninguna de ellas si no se ubicaran en el contexto más amplio, holístico, que supone la realidad viva. La economía, la migración, la tierra, el género... todo ello posee implicaciones en el resto de campos mencionados, significaciones e ineludibles referencias mutuas, plurales.

La introducción de la obra consta de dos partes, que denotan los elementos clave y vertebradores de las jornadas mismas y el volumen al que han dado luz. Nos insta primeramente Beatriz Suárez (Fundación Habitáfrica) a "Situar África como centro de producción del conocimiento", en una primera presentación generalista y a modo de declaración de intenciones de las jornadas y la obra en conjunto. Ello, por cierto, supone un desafío estructural en la era académica que habitamos, por así decir, donde el prurito por la métrica de la calidad de la ciencia desarrollada por cada país está alcanzando insospechadas cotas, consensos, críticas y controversias, y cuando lo cuantitativo parece haber ganado, si no la guerra, sí al menos una batalla importante a lo cualitativo. Por su parte, Susana Moreno (Universidad de Sevilla) centra el inicio del discurso en "Repensando África y la Universidad", poniendo el acento en la necesidad de desmontar los sesgos de la imagen occidental de África y mencionando potentes centros científicos en la África actual como CODESRIA o ENDA (santuarios del saber donde, sin embargo, 
no suelen preferir acudir los académicos occidentales cuando necesitan engrosar currículum rápido para medrar en sus carreras, y prefieren acudir a los indiscutibles santuarios occidentales como Berkeley o Nueva York, que ostentan los primeros puestos en el Ranking de Shangai, por ejemplo.)

\section{ITINERARIOS TEMÁTICOS Y TRANSVERSALES DE LA OBRA: LOS CAPÍTULOS Y SUS TEXTOS}

Tras la militante presentación de la obra, arriba descrita, en las líneas generales apuntadas sobre la importancia de significar África como centro de producción de conocimiento (también académico en sus redes y universidades), nos hallamos con el primer capítulo, "Etnocentrismos, culturas africanas y género", que cuenta con las siguientes dos aportaciones complementarias: una primera a cargo de Soledad Vieitez Cerdeño (Universidad de Granada), que ofrece un marco general para repensar los estudios africanos desde la universidad con las claves de los géneros, feminismos y culturas africanas; y una segunda, de Agnés Agboton, que opera a modo de vivo ejemplo sobre algunas de las cuestiones fundamentales apuntadas, en lenguaje teórico, en el primer texto.

El primer texto, con el título "Géneros, feminismos y culturas africanas: repensando los estudios africanos desde la universidad", da cuenta de las principales líneas de investigación por donde se están repensando los estudios africanos en la universidad contemporánea del contexto español, con el fin de crear una visión más realista e informada sobre las cuestiones mencionadas en dicho título. Son estas cuestiones cruciales en África, pero no solo en África. ¿Están las mujeres mejor cuando "entran" en el mercado laboral "formal" a través del empleo, por ejemplo? ¿Qué significa progreso o avance de género(s)? ¿Cómo formulamos los mismos géneros y cómo debatimos sobre un dualismo que en África nació ya obsoleto? En esto, como en tantas cosas, podemos fijarnos en África y sus experiencias plurales para cuestionarnos a nosotras mismas en Occidente, y tantas fallidas "revoluciones de género" que solo han patriarcalizado la idea de lo que sea avanzar o liberarse. Además del análisis epistemológico, el texto menciona interesantes iniciativas, entre la academia y el mundo de la vida, como la del Grupo de Investigación AFRICAInEs o la consultoría-empresa PERIFERIA.

La segunda contribución en este capítulo, a cargo de Agnés Agbotón y con el peculiar título de "Asunto de pescado ahumado", opera a modo de vivo ejemplo sobre algunas de las cuestiones fundamentales apuntadas, en lenguaje teórico, en el anterior texto. A través de la inapelable, tierna sabiduría de los cuentos tradicionales (en este caso, los amorosos), en su juego timador de metáforas y símbolos equívocos, se nos revela cómo ciertos pueblos han desarrollado sus propias maneras críticas de contestar a una sola forma de amar, de comprender la corporalidad erótica y emocional, desafiando incluso 
muchos de nuestros estereotipos occidentales y contra el asumido patriarcado.

El capítulo 2, “ ¿Una economía para y desde los africanos/as?”, aborda como muestra su nombre el complejo tema de la economía (que nunca es solo una cuestión económica, como bien ha vindicado la antropología). Se subdivide en cuatro textos, distintas aportaciones igualmente complementarias entre sí: las dos primeras tratan de la cuestión económica de un modo más generalista y reflexivo; las dos segundas presentan casos de estudio concretos en Tanzania, ilustrativos de la teoría.

Susana Moreno Maestro (Universidad de Sevilla), en el texto "Economía y cultura. Interpretaciones etnocéntricas de realidades sociales africanas", pretende fundamentalmente justificar la vinculación esencial entre económica y cultura, cuestionando la universalidad de los presupuestos (como el de la maximización ad infinitum) de las teorías clásicas económicas de cuño occidental, así como la generalización que la globalización ha supuesto en este sentido. Frente a ello, muestra cómo el pluralismo cultural en África opera como resistencia, a menudo a través de los cauces cuestionablemente llamados informales.

En cuanto al segundo texto de este capítulo, en la misma estela, "Desarrollo y desinstitucionalización del estado en África: hacia una nueva relación de poder", escrito a seis manos por Fernando López Castellano, Carmen Lizarraga Mollinedo y Roser Manzanera Ruiz (Universidad de Granada), encontramos una reflexión crítica sobre las explicaciones del análisis económico ortodoxo acerca del proceso histórico de formación del Estado y de la colonización, y una apuesta definitiva por hermenéuticas historiográficas genuinamente africanas.

Las dos siguientes aportaciones, "Cambios socioeconómicos en Tanzania y su influencia en las relaciones de género y en las estrategias de las mujeres rurales" y "Aspectos institucionales y socioambientales de la movilidad urbana: el caso de Dar Es Salaam (Tanzania)" (ambos con el mismo trío autorial que el anterior texto), constituyen ejemplos prácticos y reales sobre los cuestionamientos y debates básicos de los dos primeros textos. Así, se constata en ellos, para el caso concreto de Tanzania, cómo las diversas poblaciones africanas generan recursos y estrategias propios frente a dilemas arquetípicos de la globalización y tras la era colonial, como puedan ser el kibaty, en tanto que alternativa, o los conflictos novedosos sobre movilidad urbana en contextos como Dar Es Salaam, en tanto que ejemplo de contradicción contemporánea entre políticas y proyectos desarrollistas impuestos al respecto sin un criterio estructural de bienestar social.

El capítulo 3, "Panorama de las migraciones africanas", se compone de cinco contribuciones que abordan distintos aspectos -generales, regionales, teóricos- al respecto de la migración. Emma Martín Díaz (Universidad de Sevilla) ofrece un primer texto homónimo a modo de marco reflexivo o panorámico sobre las migraciones africanas, tanto para deconstruir algunos mitos sobre sus causas cuanto para proporcionar unas 
bases imprescindibles para su correcta contextualización. En la misma estela pero impostando una mirada diacrónico-histórica, Mohamed Abdillhai Bahdon continúa, con el título "Las dinámicas locales y globales de las migraciones africanas de los siglos XX y XXI: cambios sociales y políticos", aportando un formidable y riquísimo análisis de la movilidad regional señalada y sus razones, de ayer y hoy.

Isabel Marín Sánchez (Universidad de Granada), en su aportación "Emigrar o permanecer: repensando los prismas sobre la migración y el desarrollo en el norte de África”, aborda algunos de los interrogantes clave en torno al binomio migración-desarrollo para el caso magrebí, y cómo la realidad y la autonomía de las personas suelen desafiar las grandes políticas (trans)nacionales al respecto, cuyos objetivos últimos distan mucho de ser humanitarios y obedecen, en general, a las leyes del mercado financiero.

$M^{a}$ Eugenia Gutiérrez Jiménez (Universidad de Sevilla) plantea críticamente en "La imagen mediada de África: entre la simplificación y lo tribal" la fundamental cuestión de los imaginarios que transmiten los medios de comunicación españoles sobre África y "lo africano", para tratar de comprender tanto cómo se construyen los estereotipos cuanto los posibles modos de desvanecerlos y sustituirlos por imágenes más justas y certeras. Finalmente, Cristina Follana Kerfant (Fundación Habitáfrica), con el texto "Cómo incluir el aporte de las personas inmigrantes y emigrantes instaladas en la Subregión de África del oeste en las acciones de desarrollo local", nos proporciona el broche práctico y aplicado para clausurar este plural capítulo, aportando las conclusiones fundamentales del foro celebrado entre la Fundación Habitáfrica y distintas entidades públicas y privadas con inquietudes comunes.

El capítulo 4, "La riqueza natural en África: la importancia de la tierra", es menor en extensión (solo dos textos) pero no en importancia, ya que trata de asuntos de candente actualidad en los estudios africanistas contemporáneos. Reis Luis (abogado y activista angoleño) reflexiona sobre "La riqueza natural en África: la importancia de la tierra"; la tierra en África como "Una riqueza que va más allá del valor financiero. La tierra es el pan, es vida. Es además un elemento cultural que une los antepasados y los vivos" (p. 120), para aterrizar en el caso de Angola y describir analíticamente los problemas actuales sobre la gestión territorial en el continente africano.

Por su parte, Juan Pablo Aris Escarcena (Universidad de Sevilla), con el título "La soberanía alimentaria, crisis y lógica neoliberal en África”, pretende abordar la crisis alimentaria en África desde una perspectiva sistémica, no como un problema aislado solventable a través de ayudas extraordinarias o rescates; reconocimiento sistémico de crisis que sería perfectamente trasladable al contexto global en cuanto al sistema financiero neoliberal y sus límites ecológicos y éticos. Menciona el autor el trabajo desarrollado al respecto de la soberanía alimentaria en África por movimientos como ENDA Pronat y Vía Campesina África, como generadores de alternativas y recursos, en fin, estructurales y sostenibles frente al capitalismo. 
El capítulo 5, "Cooperación, Universidad y África", se compone de un único texto rubricado por Concepción Foronda Robles y titulado "Experiencia docente de cooperación universitaria entre la universidad de Sevilla y la universidad católica de Mozambique". Se trata de un informe profusamente descriptivo precisamente de dicha experiencia, implementada a través de la docencia universitaria de posgrado dentro del Mestrado "Deselvolvimento Local e Gestão de Turismo", en el que se desarrollaron actividades tales como asesoramiento y diseño o la impartición de un módulo sobre "Eco-turismo. Turismo e meio ambiente", además de diversas prácticas de campo. La riqueza descriptiva del texto compensa su soledad en el capítulo 5, ya que nos ilustra en gran medida sobre cómo se ha articulado, en el presente caso, la cooperación entre distintas universidades con resultados exitosos, ricos y mantenidos en el tiempo tanto para profesorado cuanto para estudiantado y agentes locales.

En un momento histórico en el que los movimientos sociales, desde las primaveras árabes, Occupy Wall Street, Yen A Marre o nuestro "mayo de 2011", han adquirido una nueva significación a través de su acuñación de una praxis y un sentido novedosos de hacer política, un capítulo (el 6) sobre "Movimientos sociales africanos" adquiere una relevancia crucial. Acaso no en vano se ha dejado el último, para que su importancia se plasme en la memoria del lector. Sin embargo, y a pesar de la singularidad única del momento actual para los movimientos sociales, en los tres textos de este capítulo hallamos una recurrente reconvención: los movimientos sociales no son nada nuevo para África. También en esto nos falla la memoria en Occidente, o la historia o la historiografía; o simplemente la humildad.

Beatriz Suárez Relinque (Fundación Habitáfrica) nombra su texto "África una historia de resistencias: de la invisibilidad de los movimientos sociales al protagonismo en el FSM Dakar 2011". En él compara movimientos sociales europeos y africanos y, sobre todo, su historiografía, cómo se han abordado y construido, para acabar tomando la experiencia del Foro Social Mundial en 2011 en Dakar como ejemplo significativo de protagonismo y activismo en las luchas africanas, con un énfasis especial en las iniciativas recientes de CODESRIA para una epistemología revisada en el análisis de África, su producción científica, etc.

Sergio Almisas Cruz (Universidad de Sevilla), con el título "Movimientos sociales y políticos africanos. Del siglo XIX al siglo XXI: una visión histórica”, realiza una sintética e interesante panorámica histórica de las resistencias e iniciativas africanas de los últimos dos siglos, antes, durante y tras los complejos períodos coloniales, en los diversos modos como ha tenido África de interactuar con Europa y el resto del mundo. El objetivo final del texto es desentrañar los procesos de lucha y resistencia africanas para (como en trabajos anteriores) limar estereotipos e imaginarios alejados de la realidad, y tratar de iluminar esta por diversos ángulos.

El capítulo 6 termina con la aportación de Cheik Adrame Sow (CEAR) a modo de 
"Reflexiones sobre los procesos de transformación impulsados por la juventud africana". Constituye un testimonio casi biográfico en el sentido de que su autor, un joven senegalés voluntario de CEAR, nos habla de su propia experiencia en el camino de transformar la realidad, desde la conciencia de protagonismo en tanto que africano y en tanto que joven. El texto, dinámico y dialógico, opera como una crónica de actualidad sobre lo que se cuece en África... sobre que África se mueve, como bien concluye su autor, y que sus protagonistas son las personas africanas.

\section{CONCLUYENDO: ÁFRICA (RE)PENSÁNDOSE}

Tras los seis capítulos temáticos, que se han desarrollado como una suerte de mosaico transescalar, en tres dimensiones, de distintas temáticas, inquietudes, bagajes, disciplinas... miradas, en fin, llegamos a la parte conclusiva y final, denominada en una retórica de franca militancia "Uniendo fuerzas para repensar África”.

Encontramos ahí una breve descripción nominativa de los distintos colectivos, asociaciones e iniciativas participantes en el proyecto, las jornadas y la obra final, como un crédito debido al carácter coral del libro: ENDA SYSPRO2 (Senegal), Asociación de Jóvenes Pescadores y Air Marine Protege (Joal Fadiouth-Senegal), MAD AFRICA (Andalucía, España), APPICA, Asociación Portal Progresivo de Inmigración y Cultura Africana, Asociación de Estudiantes Senegaleses en la Universidad de Sevilla y Almería, Asociación Cultural y Cooperación con África "El Gulmu" (Andalucía, España), Roots Africa Percusión (Andalucía, España), Grupo África (Andalucía, España), Oficina de Cooperación Internacional de la Universidad de Sevilla (Andalucía, España) y la Fundación Euroárabe de Altos Estudios (Andalucía, España). Se describe también la función desarrollada por el sitio web Repensando África y un breve recorrido por sus fundamentales contenidos. Finalmente, como es debido, se termina el libro con múltiples y necesarios agradecimientos y reconocimientos.

En suma, nos hallamos ante una obra ${ }^{2}$ útil tanto para especialistas cuanto para cualquier persona interesada en asuntos africanos, así como para el estudiante que se inicia, incluso al primer nivel de grado. Una obra que, esperamos, no se agote en sí misma sino que sea

2. A modo de humilde fe de erratas, indicamos algunos errores menores hallados en esta primera edición en cuestiones formales. El nombre de Juan Pablo Aris Escarcena aparece mal reseñado (como "Ruiz" en lugar de Aris), y tanto en su caso como en el de Sergio Almisas Cruz no se indica su adscripción institucional, la Universidad de Servilla (todo ello sí indicado aquí). Se ha detectado asimismo algún error en la consignación de páginas en el índice, que no corresponde con la realidad, como en el caso del capítulo de Susana Moreno. Todos ellos, se insiste, constituyen errores menores, habituales en cualquier obra editada, y que no restan calidad en modo alguno al conjunto del libro ni a su formato considerado de modo holístico. 
semilla de futuras y ricas nuevas colaboraciones, cristalicen o no en libros escritos, como es hoy el caso.

Pero, sobre todo, contemplamos una obra rabiosamente empírica a la par que combativamente teórica y comprometida; una obra viva, sumamente actual y contemporánea en sus inquietudes, generada a pie de tierra pero que eleva sus miras valorativas, mucho más allá de la mera descripción, al horizonte desiderativo de un mundo más justo, y no según una justicia de corte (solo) occidental sino, precisamente, una concepción pluricultural y fáctica de lo que deba ser un necesario mundo mejor; la justicia epistemológica de la que habla Sousa Santos, que bien recuerda Susana Moreno en este libro, y que puede resumirse en reconocer lo que sabe cada cual y actuar en consecuencia.

Una obra, en fin, cuyo título formulado en gerundio, "repensando África", informa sobre lo hecho y sobre lo que está colectivamente pendiente, dando cuenta no solo del ejercicio de revisita epistemológica sino, muy especialmente, de la voluntad descolonizadora, y también decolonial, que habita en sus páginas. Ello es reflejo fiel de la estela del pensamiento más contemporáneo y crítico sobre altermundialismo; estela actual pero también, justo es decirlo, heredera legítima y directa de los primeros que, hace ya décadas, empuñaron tales conceptos como armas en África, y desde allí como ejemplo para el mundo: “También a nosotros, los europeos, nos están descolonizando [...]”, clamaba Sartre, prologando a Fanon en su inmortal obra, canónica para cualquier africanista. En ese deseo de descolonizar-nos, y de que nos descolonicen, ha nacido este libro y se invita a su lectura.

\section{REFERENCIAS BIBLIOGRÁFICAS}

SARAMAGO, José (2003) Viaje a Portugal. Madrid: Santillana. 